\title{
PROBABILISTIC SEISMIC PERFORMANCE EVALUATION OF NON-SEISMIC RC FRAME BUILDINGS
}

\author{
M.M. Maniyar ${ }^{1 *}$, R.K. Khare ${ }^{2}$, R. P. Dhakal ${ }^{3}$
}

ABSTRACT

In this paper, probabilistic seismic performance assessment of a typical non-seismic RC frame building representative of a large inventory of existing buildings in developing countries is conducted. Nonlinear time-history analyses of the sample building are performed with 20 large-magnitude medium distance ground motions scaled to different levels of intensity represented by peak ground acceleration and 5\% damped elastic spectral acceleration at the first mode period of the building. The hysteretic model used in the analyses accommodates stiffness degradation, ductility-based strength decay, hysteretic energy-based strength decay and pinching due to gap opening and closing. The maximum inter story drift ratios obtained from the time-history analyses are plotted against the ground motion intensities. A method is defined for obtaining the yielding and collapse capacity of the analyzed structure using these curves. The fragility curves for yielding and collapse damage levels are developed by statistically interpreting the results of the time-history analyses. Hazard-survival curves are generated by changing the horizontal axis of the fragility curves from ground motion intensities to their annual probability of exceedance using the log-log linear ground motion hazard model. The results express at a glance the probabilities of yielding and collapse against various levels of ground motion intensities.

Key words: Non-seismic; RC frames; Incremental Dynamic Analysis (IDA); Seismic performance; Fragility curves; Yielding; Collapse; Hazard survival

\section{Introduction}

Low and medium rise non-seismic RC frame buildings designed only for gravity loads constitute the major stock of existing buildings in developing countries like India. Recent earthquakes have exposed the lack of seismic resistance of such non-seismic RC framed buildings. Collapse of numerous RC frame buildings during the Bhuj earthquake (2001) has emphasized the need for risk assessment of existing building stock for estimating the potential damage from future earthquakes. It is important to evaluate such buildings and improve their seismic resistance if they are found to be vulnerable. The World Housing Encyclopedia Report presented by EERI (Jaiswal et al., 2003) mentions that RC buildings with brick masonry infill walls designed for gravity loads performed very poorly during the Bhuj earthquake of January 2001 in which several thousands of such buildings collapsed. The collapse was not limited to the epicentral region. About $75 \mathrm{RC}$ frame buildings collapsed and several thousand others were damaged in and around Ahmadabad, which is over $250 \mathrm{~km}$ from the epicenter, clearly demonstrating the seismic vulnerability of this type of construction.

The awareness of the potential seismic risk and corresponding seismic vulnerability of existing building stock has risen in response to the economic and social effects of recent earthquakes on urban areas. Seismic risk analysis of such buildings is important for identifying the seismic vulnerability under the effect of potential seismic hazard. This approach is useful for retrofitting decisions, damage estimation, loss estimation and disaster response planning. Identifying potential hazards ahead of time

\footnotetext{
${ }_{1}^{1}$ Senior Lecturer, Department of Structural Engineering, S.P.C.E., Mumbai -400058, India.( *Corresponding author)

${ }^{2}$ Professor, Department of Civil Engineering, S.G. S. Institute of Technology \& Science, Indore - 452003, India

${ }^{3}$ Senior Lecturer, Department of Civil Engineering, University of Canterbury, Private Bag 4800, Christchurch, NZ
} 
and advance planning can save lives and significantly reduce injuries and property damage. Performance assessment under the expected seismic load is one of the objectives of a performance-based design. There is an urgent need to accelerate this process of quantification of vulnerability by conducting rigorous analysis using the available tools which involve realistic material and structural models capable of predicting dynamic response of structures. Incremental Dynamic Analysis (IDA) is a viable choice for this purpose (Vamvatsikos and Cornell, 2002). The use of probabilistic procedures to estimate structural damage and loss in earthquakes is justified due to the uncertain nature of future ground motions. For this purpose, fragility curves can be used to estimate the probability of structural damage due to ground motions of different Intensity Measures (IM), such as Peak Ground Acceleration (PGA), elastic spectral acceleration $\left(\mathrm{S}_{\mathrm{a}}\right)$, elastic spectral displacement $\left(\mathrm{S}_{\mathrm{d}}\right)$ etc.

In this study, a representative 4 story non-seismic RC frame building is designed according to the former version of the Indian RC design code IS 456:1978. Only yielding and collapse damage levels are considered, since they can be determined analytically with reasonable accuracy. Under the effect of twenty large magnitude medium distance ground motions, IDA are performed to determine the yielding and collapse capacity of the sample buildings in terms of PGA and $\mathrm{S}_{\mathrm{a}}$. Those capacities are evaluated by statistical methods to develop the fragility curves.

\section{Performance assessment methods}

\subsection{Nonlinear static procedure}

The nonlinear static procedure has become a popular tool among practicing engineers for estimating seismic deformation demands in building structures as well as their local and global capacities for the evaluation of the safety of existing structures against probable future earthquakes. It was introduced in FEMA-273 (1997) and has been updated in FEMA-356 (2000) and recently in FEMA-440 (2005). This procedure is recommended for structures in which "higher mode effects" are not significant. If higher mode effects are significant, then this procedure needs to be supplemented with a linear dynamic analysis. In FEMA-356's nonlinear static procedure, a model of the structure is constructed considering explicitly the nonlinear force-deformation behavior of its elements. Then, a base shear-lateral displacement relationship is established by subjecting this model to monotonically increasing lateral forces with a prescribed height-wise distribution, until the displacement of a control node (usually, the center of mass of the building's roof), or the maximum inter-story drift exceeds a target magnitude or the structure collapses. The target displacement/drift is intended to represent the maximum displacement/drift likely to be experienced by the structure under a selected seismic hazard level. Various structural demands (such as, element forces, story drifts, plastic hinge rotations, etc.) at this target displacement are then compared against a series of prescribed acceptability criteria. These acceptability criteria depend on the construction material (steel, reinforced concrete, etc.), member type (beam, column, etc.), member importance (primary or secondary), and a pre-selected performance level ("operational", "immediate occupancy", "life safety", or "collapse prevention"). A global collapse is assumed to occur whenever the base shear-lateral displacement curve attains a considerable negative slope (due to $P$ - $\Delta$ effects) and reaches afterward a point of zero or 
negligible base shear. Such a point implies no lateral resistance and the inability of the structure to resist gravity loads.

This procedure is based on questionable assumptions that the nonlinear response of a structure can be related to the response of an equivalent single degree-of-freedom system and that the distribution of the equivalent lateral forces over the height of the structure remains constant during the entire duration of the structural response (both elastic and inelastic). Moreover, it also neglects the duration and cyclic effects, the progressive changes in the dynamic properties that take place in a structure as it experiences yielding and unloading during an earthquake, the fact that nonlinear structural behavior is load-path dependent, and the fact that the deformation demands depend on ground motion characteristics. In fact, in correlation with the observed damage in several of the buildings damaged during the 1994 Northridge earthquake and comparisons with results from nonlinear time-history analyses, several investigators (Gupta and Kunnath, 2000; Chopra and Goel, 2004) have found that the procedure does not provide an accurate assessment of building behavior. It may lead to gross underestimation of story drifts and may fail to identify correctly the location of plastic hinges. This is particularly true for structures that deform far into their inelastic range of behavior and undergo a significant degradation in lateral capacity. In recognition of these deficiencies, improved nonlinear static procedures have been proposed. Among these improved procedures are those that use a time-variant distribution of the equivalent lateral forces (Gupta and Kunnath, 2000) and those that consider the contribution of higher modes (Chopra and Goel, 2002; Goel and Chopra, 2005). These improved procedures lead to better prediction in some cases, but none has been proven to be universally applicable. It is doubtful, thus, that nonlinear static methods may be used reliably to predict the collapse capacity of structures and estimate their margin of safety against a global collapse.

\subsection{Incremental dynamic analysis (IDA)}

IDA has recently emerged as a powerful mean to study the overall behavior of structures, from their elastic response through yielding and nonlinear response and all the way to global dynamic instability. It has been adopted by FEMA-350 (2000) guidelines and established as the state-of-the-art method to determine global collapse capacity. IDA involves performing a series of nonlinear dynamic analyses in which the intensity of a selected ground motion is incrementally increased until the global collapse capacity of the structure is reached. By analogy with passing from a single static analysis to the incremental static pushover, one arrives at the extension of a single time-history analysis into an incremental one, where the seismic "loading" is scaled. The concept has been mentioned as early as 1977 by Bertero.

Through IDA, one can plot the interrelationship between an IM of the ground motion (e.g. $\mathrm{S}_{\mathrm{a}}$ or PGA) against an Engineering Demand Parameter (EDP) of the structure, such as peak inter story drift ratio. As different ground motions (i.e., ground motions with different frequency content and different durations) lead to different intensity versus response plots, the analysis is repeated under different ground motions to obtain meaningful statistical averages.

Vamvatsikos and Cornell (2002) have described the method in detail, determined intensity-response curves for several structures, examined the properties of these response-intensity curves, proposed techniques to perform efficiently an IDA and 
summarized the information obtained from different curves that different ground motions produce. They have observed that IDA is a valuable tool that simultaneously addresses the seismic demands on structures and their global capacities. These analyses also draw attention to some unusual properties of the response-intensity curves such as nonmonotonic behavior, discontinuities, multiple collapse capacities, and their variability from ground motion to ground motion. Recently, IDA has been extensively applied in Performance Based Earthquake Engineering (PBEE); such as in identification of critical ground motions (Dhakal et al., 2006) for multi-level seismic performance assessment (Bradley et al., 2008), and for seismic risk assessment of bridges (Mander et al., 2007) and seismic RC frame buildings (Solberg et al., 2008). As IDA is more powerful and sophisticated than the nonlinear static procedure, IDA is applied to investigate the seismic performance of the typical non-seismic RC frame building in this study.

\subsection{Evaluation of collapse capacity}

Ibarra and Krawinkler (2004) have proposed a methodology to evaluate global collapse capacity of deteriorating frame structures under earthquake ground motions. The methodology was based on the use of a relative IM, which they defined as $S_{a}\left(T_{1}\right) / g / \gamma$, where $S_{a}\left(T_{1}\right)$ denotes the $5 \%$ damping elastic spectral acceleration at $T_{1}$, the fundamental period of the structure; $g$ is the acceleration due to gravity; and $\gamma$ is a base shear coefficient equal to $\mathrm{V}_{\mathrm{y}} / \mathrm{W}$, where $\mathrm{V}_{\mathrm{y}}=$ yield base shear without $\mathrm{P}-\Delta$ effects and $\mathrm{W}=$ weight of the structure. For structures with no over strength, this IM is equivalent to the reduction factor used in building codes for the analysis of yielding structures. The methodology was also based on the use of deteriorating hysteretic models to represent the cyclic behavior of the structural components under large inelastic deformations. These deteriorating models reproduced the important modes of deterioration observed in experimental tests. To evaluate collapse capacity, they increased the ground motion intensity until the IM versus EDP curve became flat. The relative intensity at which this curve became flat was then considered to be the collapse capacity of the structure. The evaluation was made using a probabilistic format to consider the uncertainties in the frequency content of ground motions and the deterioration characteristics of the structural elements. Similar approach is used in this study to assess seismic performance of typical non-seismic RC frame buildings.

\section{Representative RC frame building}

The sample building is representative of a significant stock of urban residential buildings in developing countries. Fig. 1 a shows the typical floor plan of the sample building and Fig. $1 \mathrm{~b}$ shows the elevation of a typical frame in the sample building. The plan of the sample building constitutes of common open passage in front of two rooms per tenements which is a common feature of major portion of junior level government servants' residential quarters, transit quarters, slum rehabilitation schemes, labor colonies and lower income group housings in India. A high aspect ratio in plan and side elevation is a common feature of these types of buildings. The structural system of the representative sample building consists of RC frames, which support brick walls and slabs. The supporting beams rest on columns which rest on isolated footings. The typical story height is $2.9 \mathrm{~m}$. Concrete slabs, with a thickness of $100 \mathrm{~mm}$, are provided at floor levels.

The 4 storey sample RC residential building considered in this study is designed according to the 1978 version of the Indian RC design code (IS 456:1978). Although the 
code has been revised in 2000 , the former version is used for the design of the sample building, because buildings represented by the one under consideration were generally constructed in India before 2000. As per the practice existing then, the horizontal floor grid is designed considering pinned supports at the columns. The columns are designed only for axial loads transferred from the floor with minimum eccentricity. Typical non ductile detailing is considered at beam column joints as shown in Fig $1 \mathrm{c}$.

Two dimensional nonlinear dynamic analyses are performed for $\mathrm{X}$ direction (shorter direction) for the typical frame as the first mode of vibration of the 3dimensional model of the building is observed along $\mathrm{X}$ direction. Soil-structure interaction is not considered and the bases of the columns at the ground floor are designed for axial loads only. Following the common practice before 2000, the characteristic compressive strength of concrete is assumed to be $15 \mathrm{~N} / \mathrm{mm}^{2}$ for the design of the sample building. Fe 415 grade steel (with characteristic yield strength of 415 $\mathrm{N} / \mathrm{mm}^{2}$ ) is considered for reinforcement. The infill brick walls are neglected in the model as they are very thin $(100 \mathrm{~mm})$ and have significant openings. After performing the modal analysis for the typical $\mathrm{X}$ direction frame the fundamental period comes out to be $0.80 \mathrm{sec}$.

As shown in Fig. 2 a, the modified Kent \& Park (1971) model is used to describe the stress-strain relationship of the concrete. The confinement effect is neglected, since transverse reinforcement of the columns and beam ends of the existing buildings does not provide a significant confinement. As shown in Fig. 2 b, a bilinear stress-strain relationship with strain hardening is used for the reinforcement.

\section{Hysteretic model used for IDA}

Modeling the hysteretic behavior of structural elements is one of the core aspects of a nonlinear structural analysis. In this study, columns and beams have been modeled using a modified four-parameter moment-curvature relationship proposed by Sivaselvan and Reinhorn (1999). This hysteretic model can accommodate stiffness degradation, ductilitybased strength decay, hysteretic energy-based strength decay and pinching due to gap opening and closing through the four parameters $\alpha, \beta_{1}, \beta_{2}$ and $\gamma$, respectively. A variety of hysteresis properties can be obtained through the combination of a tri-linear skeleton curve and the four parameters $\alpha, \beta_{1}, \beta_{2}$ and $\gamma$.

\subsection{Stiffness degradation}

The elastic stiffness degrades in repeated loading cycles with increasing ductility demand. It has been found empirically that the stiffness degradation can be accurately modeled by the pivot rule (Park et al., 1987). According to this rule, the load-reversal branches are assumed to target a pivot point on the initial elastic branch at a distance of a $\alpha \mathrm{M}_{\mathrm{y}}$ on the opposite side, where $\alpha$ is the stiffness degradation parameter (Fig. 3). The parameter $\alpha$ specifies the degree of stiffness degradation, and, more importantly, the area enclosed by the hysteresis loops. The stiffness degradation factor is given by

$\mathrm{K}_{\text {cur }}=\mathrm{R}_{\mathrm{k}} \mathrm{K}_{\mathrm{o}}=\frac{\mathrm{M}_{\text {cur }}+\alpha \mathrm{M}_{\mathrm{y}}}{\mathrm{K}_{\mathrm{o}} \Phi_{\text {cur }}+\alpha \mathrm{M}_{\mathrm{y}}} \mathrm{K}_{\mathrm{o}}$

where $M_{\text {cur }}=$ current moment;

$\Phi_{\text {cur }}=$ current curvature;

$K_{0}=$ initial elastic stiffness; $\quad \alpha=$ stiffness degradation parameter; 
$M_{y}=M_{y}^{+}$if $\left(M_{c u r}, \Phi_{c u r}\right)$ is on the right side of the initial elastic branch and

$M_{y}=M_{y}^{-} \operatorname{if}\left(M_{c u r}, \Phi_{c u r}\right)$ is on the left side.

Ranges of variation of $\alpha$ indicate that for large values $(\alpha>200)$, no deterioration occurs, whereas small values $(\alpha<10)$ produce substantial degradation (Sivaselvan and Reinhorn, 1999).

\subsection{Strength degradation}

As shown in Fig. 4, strength degradation is modeled by reducing the capacity in the backbone curve. Mathematically, this is equivalent to specifying an evolution equation for the yield moment. The strength degradation rule can be formulated to include a continuous energy-based degradation in the envelope, which occurs when the maximum deformation attained in the past is exceeded. The rule can be expressed mathematically as

$$
\mathrm{M}_{\mathrm{y}}^{+/-}=\mathrm{M}_{\mathrm{y} 0}^{+/-}\left[1-\left(\frac{\Phi_{\max }^{+/-}}{\Phi_{\mathrm{u}}^{+/-}}\right)^{1 / \beta_{1}}\right]\left[1-\frac{\beta_{2}}{1-\beta_{2}} \frac{\mathrm{H}}{\mathrm{H}_{\mathrm{ult}}}\right]
$$

where $\mathrm{M}_{\mathrm{y}}^{+/-}=$positive or negative yield moment;

$\mathrm{M}_{\mathrm{y} 0}^{+/-}=$initial positive or negative yield moment;

$\Phi_{\max }^{+/-}=$maximum positive or negative curvatures;

$\Phi_{u}^{+/-}=$positive or negative ultimate curvatures;

$\mathrm{H}=$ hysteretic energy dissipated, obtained by integrating the hysteretic energy quotient;

$\mathrm{H}_{\mathrm{ult}}=$ hysteretic energy dissipated when loaded monotonically to the ultimate curvature without any degradation;

$\beta_{1}=$ ductility-based strength degradation parameter; and

$\beta_{2}=$ energy-based strength degradation parameter.

The second term on the right side of Eq. 2 represents strength degradation due to increased deformation and the third term represents strength degradation due to hysteretic energy dissipated.

\subsection{Pinching or slip}

Pinched hysteresis loops usually are a result of crack closure. The pinching behavior is introduced in the hysteresis model by lowering the target maximum point (point ' $A$ ' in Fig. 5) to a level of $\gamma \mathrm{M}_{\mathrm{y}}$ (point ' $\mathrm{B}$ ' in Fig. 5) along the previous unloading line. Reloading paths aim this new target point until they reach the crack closing deformation (' $U_{s}$ ' of Fig. 5). The stiffness of reloading path is changed at this point to aim the previous target maximum point ' $A$ '. The introduction of such a pinching behavior also leads to a reduction of hysteresis loop areas and indirectly, the amount of dissipated energy.

In order to use this four parameter hysteresis model in nonlinear dynamic analyses, the four factors need to be quantified for the structural type being analyzed. Murty et al. (2001) and Rai et al. (2006) have performed cyclic testing of RC beam column joint assemblages for typical non-seismic (designed only for gravity loads) detailing of frames constructed in India. Severe pinching of the hysteretic loops at large displacement cycles was observed in the tests. Fig. 6 shows the hysteretic behavior of test specimen as experimentally demonstrated by Rai et al. (2006). The nominal values of the 
parameters $\alpha, \beta_{1}, \beta_{2}$ and $\gamma$, based on the behavior of non-seismic RC frames under cyclic loads, are calibrated to be $100,0.15,0.08$ and 0.2 , respectively. For conducting IDA of the sample non-seismic RC frame building, these values of the four parameters are used in the hysteresis models (Sivaselvan and Reinhorn, 1999).

\subsection{Nonlinear dynamic analysis}

The increased accuracy, efficiency and speed of computational tools have made inelastic time history analysis the most promising and powerful tool for evaluating seismic response of buildings. In this study, nonlinear dynamic analysis is carried out using a combination of the Newmark-Beta integration method (Chopra, 1995) and the pseudoforce method (Park et al., 1987). The solution is carried out in incremental form, using the matrix equation:

$[\mathrm{M}]\{\Delta \ddot{\mathrm{u}}\}+[\mathrm{C}]\{\Delta \dot{\mathrm{u}}\}+\left[\mathrm{K}_{\mathrm{t}}\right]\{\Delta \mathrm{u}\}=-[\mathrm{M}]\left(\left\{\mathrm{L}_{\mathrm{h}}\right\} \Delta \ddot{\mathrm{x}}_{\mathrm{gh}}\right)+\mathrm{c}_{\text {corr }}\left\{\Delta \mathrm{F}_{\text {err }}\right\}$

Where

$(\mathrm{M})=$ The lumped mass matrix of the structure;

$(\mathrm{C})=$ the viscous damping matrix of the structure;

$\left(\mathrm{K}_{\mathrm{t}}\right)=$ is the tangent stiffness matrix;

$\mathrm{c}_{\text {corr }}=$ a correction coefficient (usually taken as one);

$\left\{\Delta \mathrm{F}_{\text {err }}\right\}=$ the vector with the unbalanced forces in the structure;

$\left\{L_{h}\right\}=$ the allocation vectors for the horizontal ground accelerations;

$\{\Delta \ddot{\mathrm{u}}\},\{\Delta \dot{\mathrm{u}}\}$ and $\{\Delta \mathrm{u}\}=$ the incremental vectors of acceleration, velocity and displacement in the structure respectively; and

$\Delta \ddot{\mathrm{x}}_{\mathrm{gh}}=$ the increment in the horizontal ground accelerations.

The solution of Equation (3) is carried out assuming a linear variation of the acceleration. To perform the unconditionally stable constant average acceleration, the parameters for numerical integration of the method are selected as $\beta=1 / 4$ and $\gamma=1 / 2$. The time step for dynamic analysis $\Delta \mathrm{t}$ is kept at 0.0001 seconds.

\section{Employment of IDA Method}

\subsection{Ground motions}

The random nature of earthquakes makes the damage estimation problem probabilistic. Shome (1999) has shown that for mid-rise buildings, ten to twenty records are usually enough to provide sufficient accuracy in the estimation of seismic demands, assuming a relatively efficient IM, like $S_{a}\left(T_{1} ; 5 \%\right)$, is used. Twenty ground motion records representative of large magnitude and medium distance earthquakes are used in this study to capture ground motion variability. Table 1 shows the set of the 20 ground motion records used by Vamvatsikos and Cornell (2002) to analyse mid-rise buildings. Some of the specific reasons behind selection of these ground motions for conducting IDA are: (a) these records are historical (i.e. real) not artificial (i.e. synthetic); (b) they cover a broad range of fundamental periods within the amplified region of response spectra applicable to mid rise structures; (c) they represent different frequency content and durations; and (d) they are from a large magnitude (i.e. 6.5-6.9) and medium distance (i.e.13 km-30 $\mathrm{km})$ bin to effectively represent a scenario earthquake for sites not located close to the faults (i.e. not exposed to near source ground motions). 
Using more than one ground motion record leads to variability in response from the randomness of input motion. Fig. 7 shows the response spectra for each of the 20 ground motions scaled to the same IM, that is $\mathrm{PGA}=1.0 \mathrm{~g}$ and $\mathrm{S}_{\mathrm{a}}(0.8 \mathrm{sec})=1.0 \mathrm{~g}$. Fig. 7 also shows the lognormal dispersion $\beta$ of $S_{a}$ (at different periods) of the 20 records scaled to the same IM for the two cases in terms of lognormal standard deviation beta. As can be seen in the figures, apart from the scaling period ( $0 \mathrm{sec}$ for PGA based scaling and $\mathrm{T}_{1}$ for $\mathrm{S}_{\mathrm{a}}$ based scaling) the responses related to other periods vary in a wide range. This indicates that regardless of how the records are scaled there will be variability in the predicted response of a structure due to the contribution of higher order modes and also due to longer period response in the nonlinear range.

\subsection{Generation of IDA Curves}

Once the structural model is created and the ground motion records are selected, IDA is performed. For this study, the maximum inter story drift ratio is used as the EDP. PGA and 5\% damped elastic spectral acceleration corresponding to the first mode (denoted hereafter as $\mathrm{S}_{\mathrm{a}}$ for brevity) are selected as the IM. To determine the collapse capacity of the structure, ground motions are scaled up from a low value of IM to higher values. IDA is carried out with an increasing level of IM till dynamic instability occurs for the first time as a result of a numerical instability at a very high IM. An increment of $0.025 \mathrm{~g}$, which is reduced to $0.01 \mathrm{~g}$ for capturing yield capacity, in PGA, is selected in order to capture the collapse capacity of the structure with a reasonable sensitivity. The IDARC2D (Park et al., 2004) computer package is used for the non-linear dynamic analyses.

Locating the maximum inter story drift observed in an analysis gives one point for the PGA (or $\mathrm{S}_{\mathrm{a}}$ ) versus maximum inter story drift plot. Connecting such points obtained from all the analyses using one earthquake record scaled to different levels of IM (PGA or $\mathrm{S}_{\mathrm{a}}$ ) gives the IDA curve for that individual earthquake. For the first ground motion record in Table 1; i.e. Loma Prieta earthquake recorded at Agnews State Hospital station (see Fig. 8). IDA curves with PGA and $\mathrm{S}_{\mathrm{a}}$ as the IM are shown in Fig. 9a and Fig.9b, respectively. Using the set of twenty ground motions, twenty IDA curves similar to the one shown in Fig. 9 are generated. The IDA curves obtained for the sample building with $\mathrm{S}_{\mathrm{a}}$ and PGA as IMs are shown in Figs. $10 \mathrm{a}$ and $10 \mathrm{~b}$, respectively. As can be observed in the figures, using $S_{a}$ as the IM results in a visibly narrow band of IDA curves until they leave the elastic path after yielding. Nevertheless, in the post-yielding phase the difference in variation of the flat IDA curves between the two cases is not as much prominent, although $\mathrm{S}_{\mathrm{a}}$ still appears to give a slightly narrower band in this range as well.

If the $20 \mathrm{EDP}$ values at an IM strip is taken, they are shown to confirm to lognormal distribution (Aslani and Miranda, 2005; Mander et al., 2007), which can be completely defined by two variables, a median and a lognormal standard deviation, also known as the dispersion factor. In Fig 10, the dispersions of EDPs at different levels of IM and of IMs at different levels of EDPs are also plotted beside and above the IDA curves. As is obvious from these figures, the dispersion is less with $S_{a}$ as the IM (than with PGA), which corroborates the outcome of previous studies (Dhakal et al., 2007) that $\mathrm{S}_{\mathrm{a}}$ in general is a more efficient IM than PGA.

To demonstrate applicability of IDA for the sample building, the ground motion time histories for Bhuj earthquake recorded at Ahmadabad station (component N12W and N78E) are chosen. Fig. 11 a and Fig. 11 b show the acceleration time history of these two records, and Fig. $11 \mathrm{c}$ and Fig. $11 \mathrm{~d}$ show IDA curves of these records for the sample 
building considering $\mathrm{S}_{\mathrm{a}}$ and PGA as IMs. Note the different order of the IDA curves for these records when plotted with the two different IMs; this is because the N78E record has much larger $\mathrm{S}_{\mathrm{a}}(5 \%, 0.8 \mathrm{sec}$ ) to PGA ratio (about 2.5) than the $\mathrm{N} 12 \mathrm{~W}$ record has (about 1.36), as can be deduced by comparing the response spectra in Figs. $11 \mathrm{e}$ and $11 \mathrm{f}$.

\section{Seismic Performance Assessment from IDA results}

\subsection{Performance levels}

In PBEE, various performance levels corresponding to different levels of EDPs have been considered in recent studies (HAZUS, 1999; Smyth et al., 2004; Shinozuka et al., 2000). A common form of damage classification is to use a numerical indicator format as adopted by HAZUS (1999). As given in Table 2 numbers from one to five that refer to increasing level of damage are used. For buildings, Smyth et al. (2004) specified four different damage levels: slight; moderate; major or extensive; and complete or collapse. Normally, maximum inter-story drift ratio is correlated to the damage measure and each damage level is expressed as a probabilistic function of the inter-story drift ratio. Usually, this is done by assuming a log normally distributed damage function which is completely defined by a median inter-story drift ratio and the lognormal standard deviation (i.e. dispersion). Almost all damage levels used in previous studies (HAZUS, 1999; Smyth et al., 2004; Shinozuka et al., 2000) have been assumed to be deterministically associated with assumed values of EDP (i.e. inter-story drift ratio) without considering any uncertainty in the EDP-DM interrelationship. Determining median values and dispersion of the EDP corresponding to different levels of damage using an analytical method is not easy. The damage-EDP relationships (usually shown graphically by using fragility curves) are normally deduced based on the results of few experiments, engineering judgment, and experience from previous earthquakes (Porter et al., 2007). Assuming damage measure arbitrarily, in terms of a predefined inter story drift ratio or any other similar EDP, will not correctly reflect the drift demands for collapse state; especially given that the type of structure under consideration is non-seismic, non ductile building.

Performance levels or limit-states are important ingredients of PBEE, and the IDA curve contains the necessary information to assess some key performance levels. For example, yielding and collapse can be determined analytically with reasonable accuracy from the IDA curves for a particular building against a particular ground motion (Kircil and Polat, 2006). Hence, yielding and collapse are considered as basic damage levels for this study. The yield capacity of the structure is defined as the IM point at which the IDA curve leaves the linear path. When the structure reaches its collapse capacity, practically, an increase in IM produces an infinite increase in EDP. Yield and collapse points, following these definitions, are indicated in Fig. 9. The collapse of a structure is defined as the condition at which the whole structure, or a significant portion of it, becomes unable to support the gravity loads during a seismic excitation. The analysis considers global (dynamic) instability (GI) as a performance level corresponding to collapse limit state. An inter story drift ratio of $3 \%$ and the corresponding IM were used to define the collapse capacity for some IDA curves which did not completely flatten until reaching $3 \%$ drift (which is too high for a non-seismic and non-ductile building). Only 2 records fell into this category and the IDA curves for these records, although not flattened completely, had only a small positive slope at $3 \%$ drift (see Figs 10 a and 10 b). As 
collapse levels are correlated with levels of IM (rather than EDP) in this study, this definition of collapse does not induce much error.

\subsection{Derivation of fragility curves}

Fragility curves express the probability of structural damage due to earthquakes as a function of EDP or IM. In the present study, fragility curves are constructed in terms of IM; i.e. $S_{\mathrm{a}}$ and PGA. It is assumed that the fragility curves can be expressed in the form of two-parameter lognormal distribution functions. Based on this assumption, the probability of the damage exceeding the limit state capacity is expressed as

$$
P(\text { Damage } \geq \text { Limit state })=\Phi\left[\frac{\ln X-\zeta}{\beta_{C / D}}\right]
$$

where $\Phi(\bullet)$ is the standard normal distribution, $X$ is the lognormally distributed IM $\left(\mathrm{S}_{\mathrm{a}}\right.$, PGA) necessary to cause the collapse damage state to occur. The median of the natural $\log$ of the $\mathrm{X}$ values $\zeta$ is estimated by computing the geometric mean of the data:

$$
\zeta=\exp (\overline{\ln X})
$$

Where $\overline{\ln X}$ is the mean of natural logarithm of $\mathrm{X}$ data.

The standard deviation of the natural $\log$ of the $X$ values $\beta_{\mathrm{C} / \mathrm{D}}$ is computed by:

$$
\beta_{\mathrm{C} / \mathrm{D}}=\sigma_{\ln \mathrm{X}}=\sqrt{\sum_{i=1}^{n} \frac{\left(\ln X_{i}-\overline{\ln X}\right)^{2}}{n-1}}
$$

Table 3 displays the yield and collapse capacity in terms of $\mathrm{S}_{\mathrm{a}}$, PGA and maximum inter story drift for the 20 records. Note that the resulting variability in response comes entirely from the randomness of the input ground motions. From the 20 data points, the median and the lognormal standard deviation are also calculated in the Table. Using these values of medians and lognormal standard deviations, fragility curves for the yield and collapse damage levels are plotted in terms of PGA and $S_{a}$ in Figs. 12 a and 12 b, respectively. The distributions of actual data from the IDA results (i.e. listed in Table 3) are also shown in the figures. As can be seen, the lognormal distribution assumption fairly captures the actual distribution of the IM values for the two damage levels considered in this study.

Table 4 shows the yield and collapse capacities of the sample building against the two ground motions recorded at Ahmadabad station during the 2001 Bhuj earthquake. Although the two records were recorded at the same station during the same seismic event, the capacity and demand of the frame predicted using these two records are noticeably different. Also note that the mean yielding and collapse capacities predicted using these two records are lower than the median values obtained from the suite of 20 ground motion records used (see Table 3). However, the mean $S_{a}$ values in Table 4 are noticeably closer to the corresponding median values in Table 3 than is the case with the PGA values, further indicating that the uncertainty in prediction will be reduced if $S_{a}$ (rather than PGA) is used as the IM.

\subsection{Calibration of seismic hazard model}

In this study, as per ATC-40 (1996) three seismic hazard levels; namely the Serviceability Earthquake (SE), Design Basis Earthquake (DBE) and Maximum Considered Earthquake (MCE), are identified as earthquakes which have respectively 50\%, 10\% and $2 \%$ probability of exceedance in 50 years. These three levels of seismic hazard have 
return periods of approximately 75 years, 475 years and 2475 years, respectively. To illustrate the methodology further, this study uses a linear relationship (in log-log scale) between the PGA of ground motions (denoted as $a_{g}$ ) and their annual probability of exceedance $\left(f_{a}\right)$

$$
a_{g}=\frac{a_{g}^{D B E}}{\left(475 f_{a}\right)^{q}}
$$

where $a_{g}{ }^{D B E}$ is the PGA of the DBE ( $10 \%$ probability of exceedance in 50 years) and $q$ is an empirical constant. If the intensity of DBE (i.e. 475 years return period) is known for a location and if $q$ is calibrated to represent local hazard data, Equation (7) can be used to correlate IM with annual frequency of exceedance. A consensus probabilistic seismic hazard map that could be implemented in seismic codes is yet to be developed for India. In the Indian seismic code of practice, IS1893(Part1):2002, the zone map is not probabilistic and the acceleration values for MCE and DBE do not correspond to any specific probability of occurrence. However the zone map given in the Indian seismic code efficiently represents the variation of the seismic hazard throughout the country. The zone factor given for a particular zone implicitly represents the PGA for the design level hazard; assumed here as DBE with 475 years return period. Moreover, the code assumes that the ratio of PGA of MCE to the PGA of DBE is 2. This study considers Ahmadabad for calibrating the constant $q$ in Equation (7). According to the zone map of India, for Ahmadabad the PGA of the DBE, $a_{g}{ }^{D B E}$, is $0.16 \mathrm{~g}$ which means that the PGA of the MCE, $a_{g}{ }^{M C E}$, is $0.32 \mathrm{~g}$. Substituting the values of $a_{g}{ }^{D B E} \& a_{g}{ }^{M C E}$ and their corresponding annual frequencies of exceedance in Equation (7), the constant $q$ is calibrated as 0.42. Using Equation (7) then, the PGA for the SE can be calculated as $0.075 \mathrm{~g}$.

\subsection{Hazard survival curves}

In order to determine survival probabilities of a structure built at a location, the seismic performance predicted through IDA is required to be combined with consensus probabilistic seismic hazard map applicable to the location. Fragility curves can now be re-plotted by changing the horizontal axis from IM to $f_{a}$ or return period in years, using the seismic hazard relationship; i.e. Equation (7) with the calibrated value of $q$ for Ahmadabad. Such curves are called damage hazard curves or hazard-survival curves and they show the probability of damage being within a limit state when a ground motion of a given annual probability occurs. Fig. 13 shows the hazard survival curves for the sample building for yielding and collapse damage states. Three vertical lines representing the annual probabilities of SE $\left(f_{a} \sim 0.013\right)$, DBE $\left(f_{a} \sim 0.002\right)$ and MCE $\left(f_{a} \sim 0.0004\right)$ are also shown in the plots for reference. The information in Fig. 13 is reinterpreted in tabular form in Table 5, which shows the probability of not exceeding (i.e. surviving) the two damage states (i.e. yielding and collapse) in ground motions of various return periods. For example, the fourth row means that if a ground motion of return period of 475 years i.e. DBE with annual frequency of 0.002 ) occurs, the probability of the response being elastic (i.e. not exceeding the yielding level) is $30 \%$; and the probability of collapse not being exceeded (i.e. collapse survival) is $75 \%$.

\section{Conclusion}


In this study, a methodology for obtaining the seismic yield and collapse capacities for a typical non-seismic RC frame building representative of a large inventory of buildings in developing countries including India is presented. A representative non-seismic RC frame building is modeled with appropriate material properties and hysteretic behavior. A set of twenty ground motions from large magnitude earthquakes recorded at medium distances from the source is used to conduct Incremental Dynamic Analysis (IDA) for assessing its seismic capacity. The seismic performance of the sample building is described in terms of yield and collapse capacities, which are derived from IDA curves. The yield capacity of the structure is defined as the level of Intensity Measure (IM; i.e. PGA or $\mathrm{S}_{\mathrm{a}}$ ) at which the IDA curve leaves the linear path. Similarly, the collapse capacity is defined as the IM level at which the IDA curve becomes horizontal. Results of IDA runs with the 20 ground motion records are used to assess the record-to-record randomness of response. Fragility curves defined as the probability of exceeding a damage level (yielding/collapse) at various levels of IM are then plotted for these two damage levels.

Probabilistic seismic performance assessment of the sample non-seismic RC frame building which is assumed to be located in Ahmadabad, India in this study reveals the following:

1. There is approximately $5 \%$ probability of collapse at a ground motion of $\mathrm{PGA}=0.12 \mathrm{~g}$ and $\mathrm{S}_{\mathrm{a}}=0.18 \mathrm{~g}$. These IM values are close to that of the ground motions $(\mathrm{N} 12 \mathrm{~W}$ and $\mathrm{N} 78 \mathrm{E})$ recorded at Ahmadabad in the event of Bhuj earthquake. The PGA of the recorded ground motions was $0.11 \mathrm{~g}$ and the $\mathrm{S}_{\mathrm{a}}$ derived at the fundamental period of the typical $\mathrm{X}$ direction frame of the sample building was $0.17 \mathrm{~g}$ for the $\mathrm{N} 12 \mathrm{~W}$ record and $0.24 \mathrm{~g}$ for the $\mathrm{N} 78 \mathrm{E}$ record. The predicted $5 \%$ probability of collapse is also in fair agreement with the observed damage of such non-seismic RC frame buildings.

2. For predicting the yielding and collapse damage states, $S_{a}$ is found to be a better IM than the PGA. However, the band widths of flattened IDA curves using the two IMs were closer to each other, indicating that the difference in efficiencies of the two IMs in predicting the collapse damage state was less pronounced than for the yielding damage state. The drift demand for a specific damage measure varies with different ground motions. Being non-seismic and non-ductile, the drift capacity of the sample structure is very low. Hence, such buildings do not possess adequate ductility to resist the earthquake demands. Since the demands for yielding and collapse vary with different ground motions, assuming damage measure in terms of a predefined drift ratio or any similar EDP is not appropriate.

3. The hazard survival curve clearly shows the deficiency of this type of buildings against SE, DBE and MCE. There is no chance of survival of any of such building under probable MCE ground motions. Under probable DBE ground motions, the probabilities of surviving yielding and collapse are $30 \%$ and $75 \%$, respectively. The probability of the building remaining elastic in probable SE ground motions is $85 \%$. The predicted $15 \%$ probability of yielding under serviceability levels and $25 \%$ probability of collapse under design levels are deemed to be too high for modern structures. Therefore, there is an urgent need of appropriate retrofitting measures for such existing buildings to enhance their earthquake resistance over a period of time. 


\section{References}

Aslani, H. and Miranda, E. (2005) "Probability based seismic response analysis," Engineering Structures, Vol. 27, 1151-1163.

ATC-40 Report, (1996), "Seismic Evaluation and Retrofit of Concrete Buildings," Volumes 1 and 2, Applied Technology Council, Redwood City, California.

Bertero, V. V. (1977), "Strength and deformation capacities of buildings under extreme environments," Structural Engineering and Structural Mechanics, K. S. Pister, ed., Prentice Hall, Englewood Cliffs, NJ, 211-215.

Bradley, B. A., Dhakal, R. P., Mander, J. B. and Li, L. (2008) "Experimental multi-level seismic performance assessment of 3D RC frame designed for damage avoidance," Earthquake Engineering and Structural Dynamics,Vol. 37, No. 1, pp. 1-20.

Chopra, A. K. (1995) Dynamics of Structures: Theory and Applications to Earthquake Engineering, Prentice-Hall: Upper Saddle River, NJ.

Chopra, A. K. and Goel, R. K. (2002) "A modal pushover analysis procedure for estimating seismic demands for buildings," Earthquake Eng. Struct. Dyn., 31(3), 561582.

Chopra, A. K. and Goel, R. K. (2004) "Evaluation of modal and FEMA pushover analyses: Vertically 'regular' and irregular generic frames," Earthquake Spectra, 20(1), 255-271.

Dhakal, R. P., Mander, J. B. and Li, L. (2006) "Identification of critical ground motions for seismic performance assessment of structures," Earthquake Engineering and Structural Dynamics, 35(8), 989-1008.

Dhakal, R.P., Singh, S. and Mander, J.B. (2007) "Effectiveness of earthquake selection and scaling method in New Zealand," Bulletin of the New Zealand Society for Earthquake Engineering, 40(3), 160-171.

FEMA-273(1997) "NEHRP guidelines for the seismic rehabilitation of buildings," Federal Emergency Management Agency, Washington, D.C.

FEMA-350(2000) "Recommended seismic design criteria for new steel moment frame buildings.” Federal Emergency Management Agency Washington, D.C.

FEMA-356(2000) "Prestandard and commentary for the seismic rehabilitation of buildings," Federal Emergency Management Agency, Washington, D.C.

FEMA-440(2005) "Improvement of Nonlinear Static Seismic Analysis Procedures," Federal Emergency Management Agency, Redwood City, California.

Goel, R. K. and Chopra, A. K. (2005) "Extension of modal pushover analysis to compute member forces," Earthquake Spectra, , 21(1), 125-139.

Gupta, B. and Kunnath, S. K. ( 2000) "Adaptive spectra-based pushover procedure for seismic evaluation of structures," Earthquake Spectra, 16(2), 367-391.

HAZUS(1999) "Earthquake loss estimation methodology," Technical Manual, National Institute of Building Sciences for Federal Emergency Management Agency, Washington, DC.

Ibarra, L. F. and Krawinkler, H. (2004), "Global collapse of deteriorating MDOF systems," Proc. 13th World Conf. on Earthquake Engineering, Vancouver, B.C., Canada, Paper No. 116. 
IS:1893(Part1)(2002) "Indian standard criteria for earthquake resistant design of structures, Part 1- General provisions and buildings," Indian Standards Institution, New Delhi.

IS:456(1978) "Indian standard code of practice for plain and reinforced concrete for general building construction," Indian Standards Institution, New Delhi.

Jaiswal, K. S. Sinha, R. and Goyal, A.(2002) "World Housing Encyclopedia Report. Country: India. Housing type: Reinforced concrete frame building with masonry infill walls designed for gravity loads," EERI, Created on: 6/5/2002, Last Modified: 7/2/2003. Kent, D.C. and Park, K. R. (1971) "Flexural Members with Confined Concrete," Journal of Structural Div. ASCE, 97(ST7), 1969-1989.

Kircil, M.S. and Polat, Z. (2006) "Fragility analysis of mid-rise RC frame buildings," Engineering Structures, 28, 1335-1345.

Mander, J.B., Dhakal, R.P., Mashiko, N. and Solberg, K.M. (2007), "Incremental dynamic analysis applied to seismic financial risk assessment of bridges," Engineering Structures, 29(10), 2662-2672.

Murty, C. V. R., Rai, D. C., Bajpai, K. K. and Jain, S. K. (2001) "Anchorage details and joint design in seismic RC frames," The Indian Concrete Journal, 274-280.

Park, Y. J., Reinhorn, A. M. and Kunnath, S. K., "IDARC: Inelastic Damage Analysis of Reinforced Concrete Frame - Shear-Wall Structures", Technical Report NCEER-870008, (1987), State University of New York at Buffalo.

Park, Y.J., Reinhorn, A.M., and Kunnath, S.K. (2006) "IDARC-2D V6.0 computer program, Inelastic damage analysis of RC building structures," State University of New York.

Porter, K., Kennedy, R. and Bachman, R. (2007) "Creating fragility functions for performance based earthquake engineering," Earthquake Spectra, 23(2), 471-489.

Rai, D.C., Thakkar, S.K. and Ramesh, U. (2006) "Behavior of seismic and non-seismic RC frames under cyclic loads," The Indian Concrete Journal, 46-52.

Shinozuka, M., Feng, M.Q., Lee, J. and Naganuma T. (2000) "Statistical analysis of fragility curves," Journal of Engineering Mechanics, 126(12), 1224-31.

Shome, N. (1999) "Probabilistic seismic demand analysis of nonlinear structures," Ph.D. dissertation, Stanford University.

Sivaselvan, M. V. and Reinhorn, A. M. (1999) "Hysteretic models for cyclic behavior of deteriorating inelastic structures," Tech. Rep. MCEER-99-0018, Multidisciplinary Ctr. for Earthquake Engrg. Res., State University of New York at Buffalo, N.Y.

Smyth, A. Altay, G. Deodatis, G. Erdik, M. Franco, G. and Gulkan, P. (2004) "Benefitcost analysis for earthquake mitigation: Evaluating measures for apartment houses in Turkey," Earthquake Spectra, 20(1), 171-203.

Solberg, K. M., Dhakal, R. P., Mander, J. B. and Bradley, B. A. (2008) "Rapid expected annual loss estimation methodology for structures," Earthquake Engineering and Structural Dynamics, 37(1), 81-101.

Vamvatsikos, D. and Cornell, A.C. (2002) "Incremental dynamic analysis," Earthquake Engineering and Structural Dynamics, 31(3), 491-514. 
Table 1 Earthquake records adopted for IDA

\begin{tabular}{|c|c|c|c|c|c|c|c|}
\hline No & Event & Year & Station & $\Phi^{* 1}$ & $\mathrm{M}^{* 2}$ & $\begin{array}{c}\mathrm{R}^{* 3} \\
(\mathrm{~km})\end{array}$ & $\begin{array}{c}\text { PGA } \\
(\mathrm{g})\end{array}$ \\
\hline 1 & Loma Prieta & 1989 & Agnews State Hospital & 90 & 6.9 & 28.2 & 0.159 \\
\hline 2 & Imperial Valley & 1979 & Plaster City & 135 & 6.5 & 31.7 & 0.057 \\
\hline 3 & Loma Prieta & 1989 & Hollister Diff. Array & 255 & 6.9 & 25.8 & 0.279 \\
\hline 4 & Loma Prieta & 1989 & Anderson Dam & 270 & 6.9 & 21.4 & 0.244 \\
\hline 5 & Loma Prieta & 1989 & Coyote Lake Dam & 285 & 6.5 & 22.3 & 0.179 \\
\hline 6 & Imperial Valley & 1979 & Cucapah & 85 & 6.9 & 23.6 & 0.309 \\
\hline 7 & Loma Prieta & 1989 & Sunnyvale Colton Ave & 270 & 6.9 & 28.8 & 0.207 \\
\hline 8 & Imperial Valley & 1979 & El Centro Array \#13 & 140 & 6.5 & 21.9 & 0.117 \\
\hline 9 & Imperial Valley & 1979 & Westmoreland Fire Sta. & 90 & 6.5 & 15.1 & 0.074 \\
\hline 10 & Loma Prieta & 1989 & Hollister South \& Pine & 0 & 6.9 & 28.8 & 0.371 \\
\hline 11 & Loma Prieta & 1989 & Sunnyvale Colton Ave & 360 & 6.9 & 28.8 & 0.209 \\
\hline 12 & Superstition Hills & 1987 & Wildlife Liquefaction Array & 90 & 6.7 & 24.4 & 0.180 \\
\hline 13 & Imperial Valley & 1979 & Chihuahua & 282 & 6.5 & 28.7 & 0.254 \\
\hline 14 & Imperial Valley & 1979 & El Centro Array \#13 & 230 & 6.5 & 21.9 & 0.139 \\
\hline 15 & Imperial Valley & 1979 & Westmoreland Fire Sta. & 180 & 6.5 & 15.1 & 0.110 \\
\hline 16 & Loma Prieta & 1989 & WAHO & 0 & 6.9 & 16.9 & 0.370 \\
\hline 17 & Superstition Hills & 1987 & Wildlife Liquefaction Array & 360 & 6.7 & 24.4 & 0.200 \\
\hline 18 & Imperial Valley & 1979 & Plaster City & 45 & 6.5 & 31.7 & 0.042 \\
\hline 19 & Loma Prieta & 1989 & Hollister Diff. Array & 165 & 6.9 & 25.8 & 0.269 \\
\hline 20 & Loma Prieta & 1989 & WAHO & 90 & 6.9 & 16.9 & 0.638 \\
\hline
\end{tabular}

${ }^{1}$ Component ${ }^{2}$ Moment Magnitudes ${ }^{3}$ Closest Distances to Fault Rupture Source: PEER Strong Motion Database, http://peer.berkeley.edu/smcat/

Table 2 Damage states index in HAZUS (HAZUS 1999)

\begin{tabular}{|l|l|l|}
\hline $\begin{array}{l}\text { Damage } \\
\text { State }\end{array}$ & $\begin{array}{l}\text { Damage } \\
\text { Descriptor }\end{array}$ & $\begin{array}{l}\text { Failure } \\
\text { Mechanism }\end{array}$ \\
\hline DS1 & None (pre-yield) & Pre-Yielding \\
\hline DS2 & Minor / Slight & $\begin{array}{l}\text { Post -Yielding } \\
\text { Minor spalling }\end{array}$ \\
\hline DS3 & Moderate & $\begin{array}{l}\text { Post -Spalling } \\
\text { Bar buckling }\end{array}$ \\
\hline DS4 & Major / Extensive & Bar fracture \\
\hline DS5 & Complete Collapse & Collapse \\
\hline
\end{tabular}


Table 3 Yield and collapse capacities of the sample building against the 20 earthquakes

\begin{tabular}{|c|c|c|c|c|c|c|c|c|}
\hline \multirow[b]{2}{*}{ No } & \multirow[b]{2}{*}{ Event } & \multirow[b]{2}{*}{ Station } & \multicolumn{3}{|c|}{ Yield capacity } & \multicolumn{3}{|c|}{ Collapse capacity } \\
\hline & & & $\begin{array}{l}\mathrm{S}_{\mathrm{a}} \\
(\mathrm{g})\end{array}$ & $\begin{array}{c}\text { PGA } \\
(\mathrm{g})\end{array}$ & $\begin{array}{c}\% \text { Inter } \\
\text { Story } \\
\text { Drift }\end{array}$ & $\begin{array}{l}\mathrm{S}_{\mathrm{a}} \\
(\mathrm{g})\end{array}$ & $\begin{array}{c}\text { PGA } \\
(\mathrm{g})\end{array}$ & $\begin{array}{c}\% \text { Inter } \\
\text { Story } \\
\text { Drift }\end{array}$ \\
\hline 1 & Loma Prieta & Agnews State Hospital & 0.11 & 0.08 & 0.26 & 0.36 & 0.25 & 1.93 \\
\hline 2 & Imperial Valley & Plaster City & 0.17 & 0.15 & 0.37 & 0.25 & 0.23 & 2.24 \\
\hline 3 & Loma Prieta & Hollister Diff. Array & 0.12 & 0.05 & 0.26 & 0.41 & 0.17 & 3.00 \\
\hline 4 & Loma Prieta & Anderson Dam & 0.15 & 0.13 & 0.34 & 0.18 & 0.15 & 2.08 \\
\hline 5 & Loma Prieta & Coyote Lake Dam & 0.20 & 0.13 & 0.45 & 0.36 & 0.23 & 2.99 \\
\hline 6 & Imperial Valley & Cucapah & 0.16 & 0.13 & 0.38 & 0.24 & 0.19 & 3.00 \\
\hline 7 & Loma Prieta & Sunnyvale Colton Ave & 0.16 & 0.09 & 0.38 & 0.35 & 0.20 & 1.83 \\
\hline 8 & Imperial Valley & El Centro Array \#13 & 0.17 & 0.16 & 0.43 & 0.20 & 0.18 & 0.77 \\
\hline 9 & Imperial Valley & Westmoreland Fire Sta. & 0.18 & 0.14 & 0.41 & 0.30 & 0.23 & 2.98 \\
\hline 10 & Loma Prieta & Hollister South \& Pine & 0.21 & 0.08 & 0.48 & 0.32 & 0.12 & 2.37 \\
\hline 11 & Loma Prieta & Sunnyvale Colton Ave & 0.23 & 0.20 & 0.56 & 0.26 & 0.22 & 2.98 \\
\hline 12 & Superstition Hills & Wildlife Liquefaction Array & 0.11 & 0.08 & 0.28 & 0.25 & 0.17 & 0.86 \\
\hline 13 & Imperial Valley & Chihuahua & 0.16 & 0.08 & 0.42 & 0.20 & 0.10 & 2.60 \\
\hline 14 & Imperial Valley & El Centro Array \#13 & 0.19 & 0.23 & 0.45 & 0.20 & 0.24 & 0.74 \\
\hline 15 & Imperial Valley & Westmoreland Fire Sta. & 0.21 & 0.17 & 0.46 & 0.25 & 0.21 & 0.66 \\
\hline 16 & Loma Prieta & WAHO & 0.11 & 0.05 & 0.24 & 0.19 & 0.08 & 0.55 \\
\hline 17 & Superstition Hills & Wildlife Liquefaction Array & 0.13 & 0.05 & 0.29 & 0.34 & 0.16 & 2.55 \\
\hline 18 & Imperial Valley & Plaster City & 0.20 & 0.23 & 0.47 & 0.24 & 0.28 & 1.70 \\
\hline 19 & Loma Prieta & Hollister Diff. Array & 0.37 & 0.15 & 0.85 & 0.38 & 0.21 & 1.64 \\
\hline 20 & Loma Prieta & WAHO & 0.20 & 0.18 & 0.44 & 0.32 & 0.29 & 1.75 \\
\hline \multicolumn{3}{|c|}{ Median } & 0.17 & 0.13 & 0.42 & 0.26 & 0.21 & 2.01 \\
\hline \multicolumn{3}{|c|}{ Lognormal standard deviation } & 0.30 & 0.49 & $0.30 *$ & 0.25 & 0.33 & $0.57 *$ \\
\hline \multicolumn{3}{|c|}{$5 \%$ probability of exceeding collapse damage state } & 0.11 & 0.06 & 0.26 & 0.18 & 0.12 & 0.8 \\
\hline
\end{tabular}

* For \% Inter Story Drift values.

Table 4 Yield and collapse capacities against ground motions recorded at Ahmadabad in Bhuj Earthquake

\begin{tabular}{|c|c|c|c|c|c|c|c|c|}
\hline \multirow{2}{*}{ No } & \multirow{2}{*}{ Event } & & \multicolumn{3}{|c|}{ Yield capacity } & \multicolumn{3}{c|}{ Collapse capacity } \\
\cline { 3 - 9 } & & Station & $\begin{array}{c}\mathrm{S}_{\mathrm{a}} \\
(\mathrm{g})\end{array}$ & $\begin{array}{c}\text { PGA } \\
(\mathrm{g})\end{array}$ & $\begin{array}{c}\text { \% Inter } \\
\text { Story } \\
\text { Drift }\end{array}$ & $\begin{array}{c}\mathrm{S}_{\mathrm{a}} \\
(\mathrm{g})\end{array}$ & $\begin{array}{c}\text { PGA } \\
(\mathrm{g})\end{array}$ & $\begin{array}{c}\text { \% Inter } \\
\text { Story } \\
\text { Drift }\end{array}$ \\
\hline A & Bhuj & Ahmadabad - Component N78E & 0.19 & 0.075 & 0.45 & 0.224 & 0.09 & 0.72 \\
\hline B & Bhuj & Ahmadabad - Component N12W & 0.11 & 0.08 & 0.31 & 0.176 & 0.13 & 0.70 \\
\hline \multicolumn{2}{|l}{ Mean for Bhuj Earthquake recorded at Ahmadabad } & $\mathbf{0 . 1 5}$ & $\mathbf{0 . 0 7 8}$ & $\mathbf{0 . 3 8}$ & $\mathbf{0 . 2 0}$ & $\mathbf{0 . 1 1}$ & $\mathbf{0 . 7 7}$ \\
\hline
\end{tabular}

Table 5 Probability of surviving different damage states

\begin{tabular}{|c|c|c|}
\hline \multirow{2}{*}{ Return period } & \multicolumn{2}{|c|}{ Probability of survival } \\
\cline { 2 - 3 } & Yield & Collapse \\
\hline 50 & 0.92 & 1.00 \\
\hline 75 & 0.85 & 1.00 \\
\hline 100 & 0.80 & 1.00 \\
\hline 475 & 0.30 & 0.75 \\
\hline 1000 & 0.14 & 0.42 \\
\hline 2500 & 0.03 & 0.07 \\
\hline
\end{tabular}




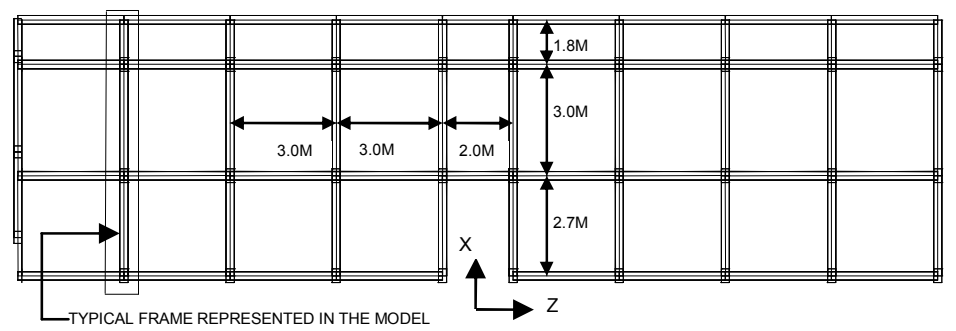

a. Typical story plan of the sample building.

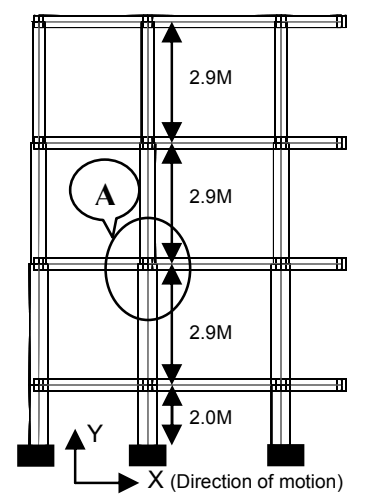

b. Elevation of the frame represented in the sample building.

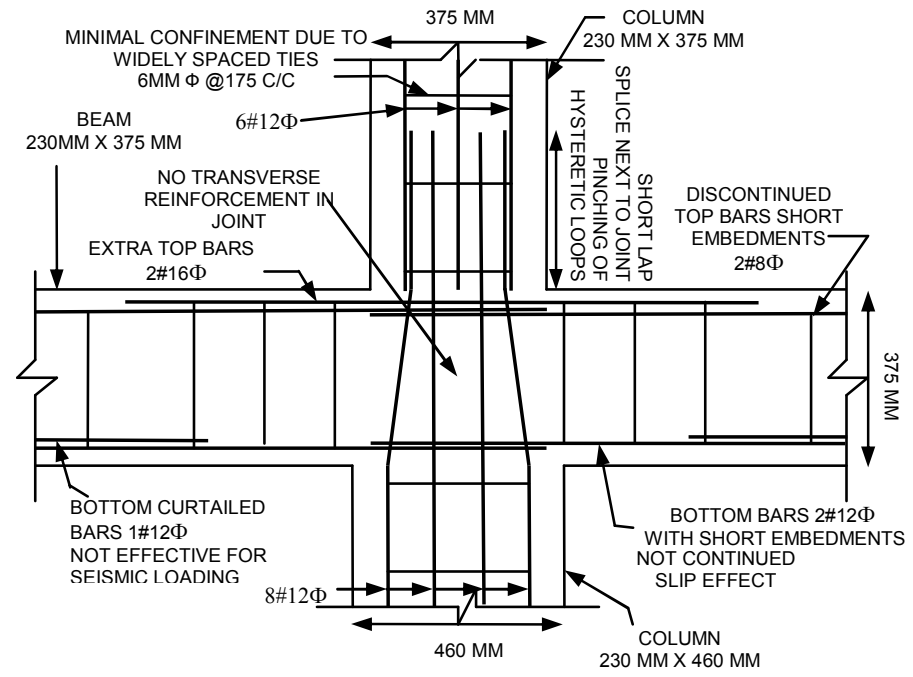

c. Typical non-seismic detailing at beam column junction marked as A.

Figure 1 Details of the typical non-seismic RC frame building adopted in the study 


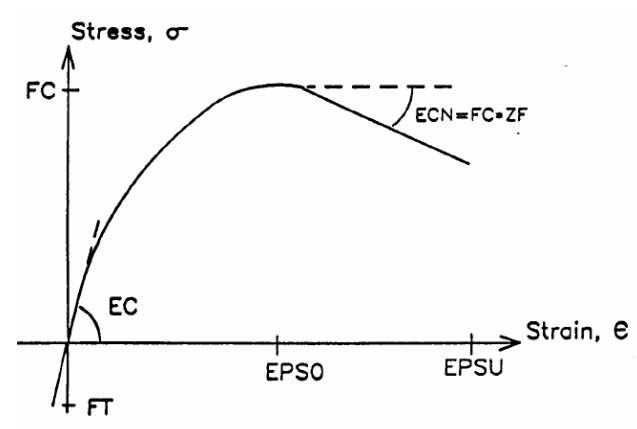

a. Concrete

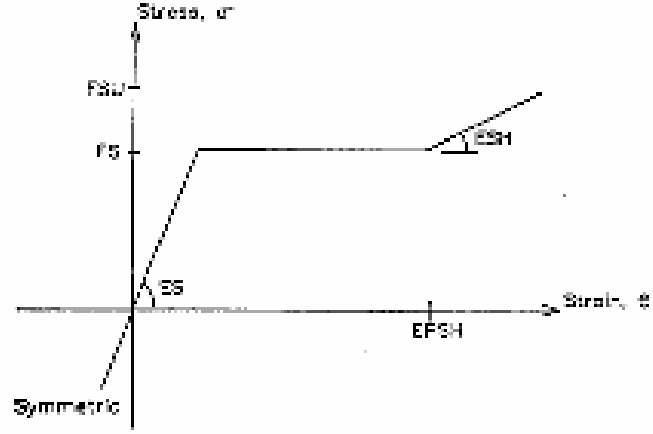

b. Reinforcing bars

Figure 2 Stress strain relationships of materials

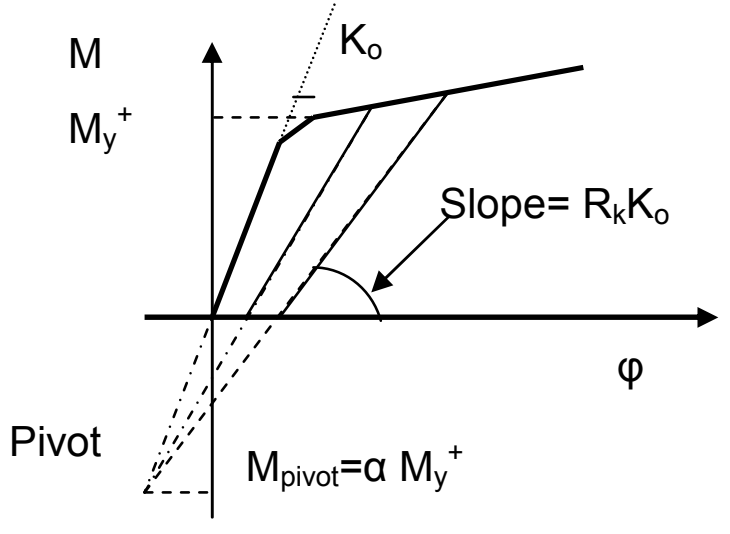

Figure 3 Modeling of Stiffness Degradation 


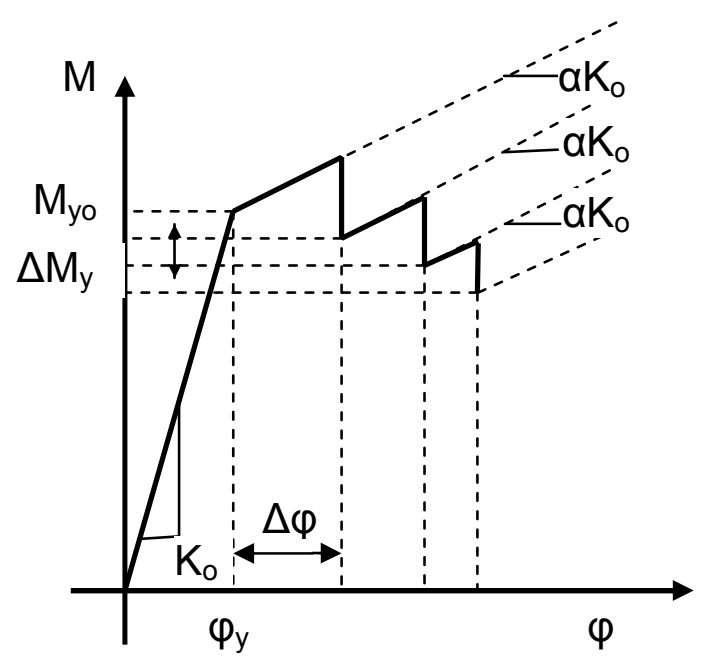

Figure 4 Modeling of Strength Degradation

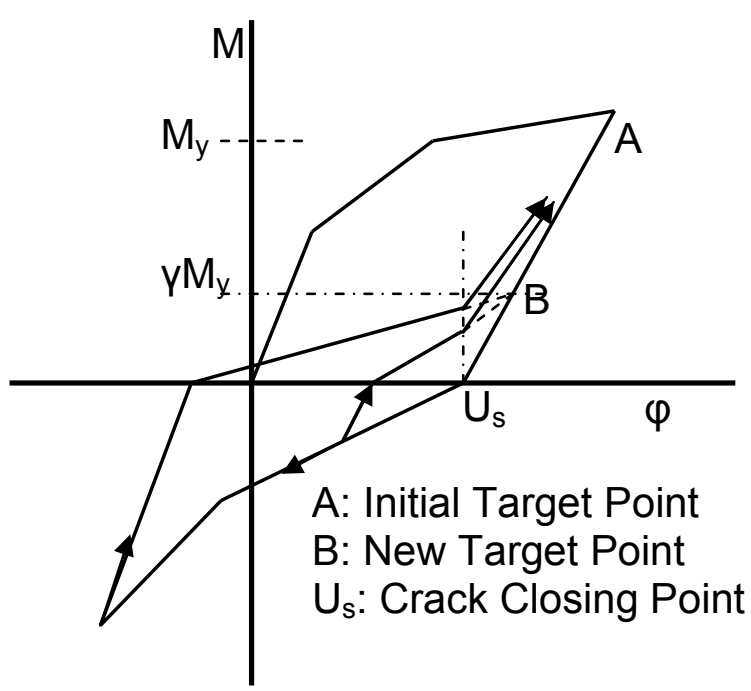

Figure 5 Modeling of Pinching or Slip 


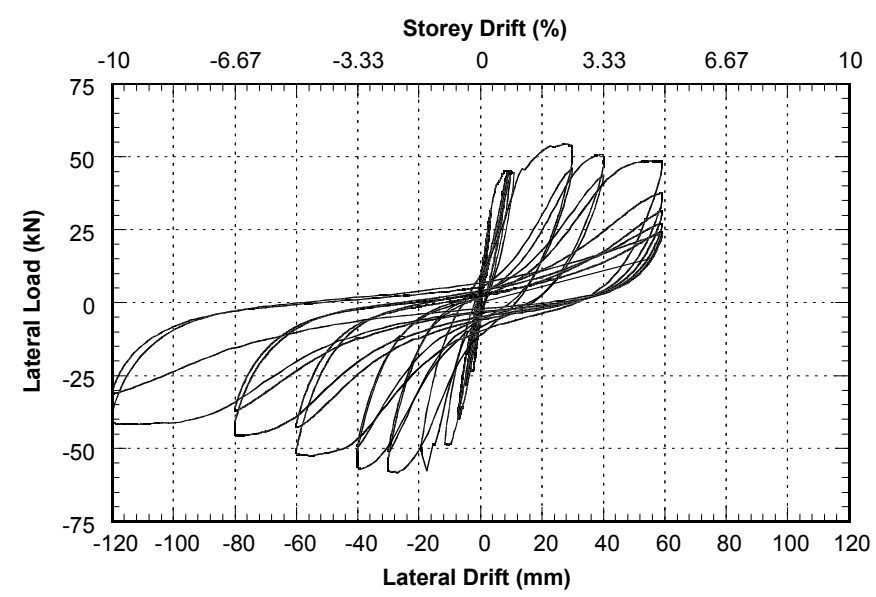

Figure 6 Hysteretic behavior of non-seismic frames (Rai et al. 2006)
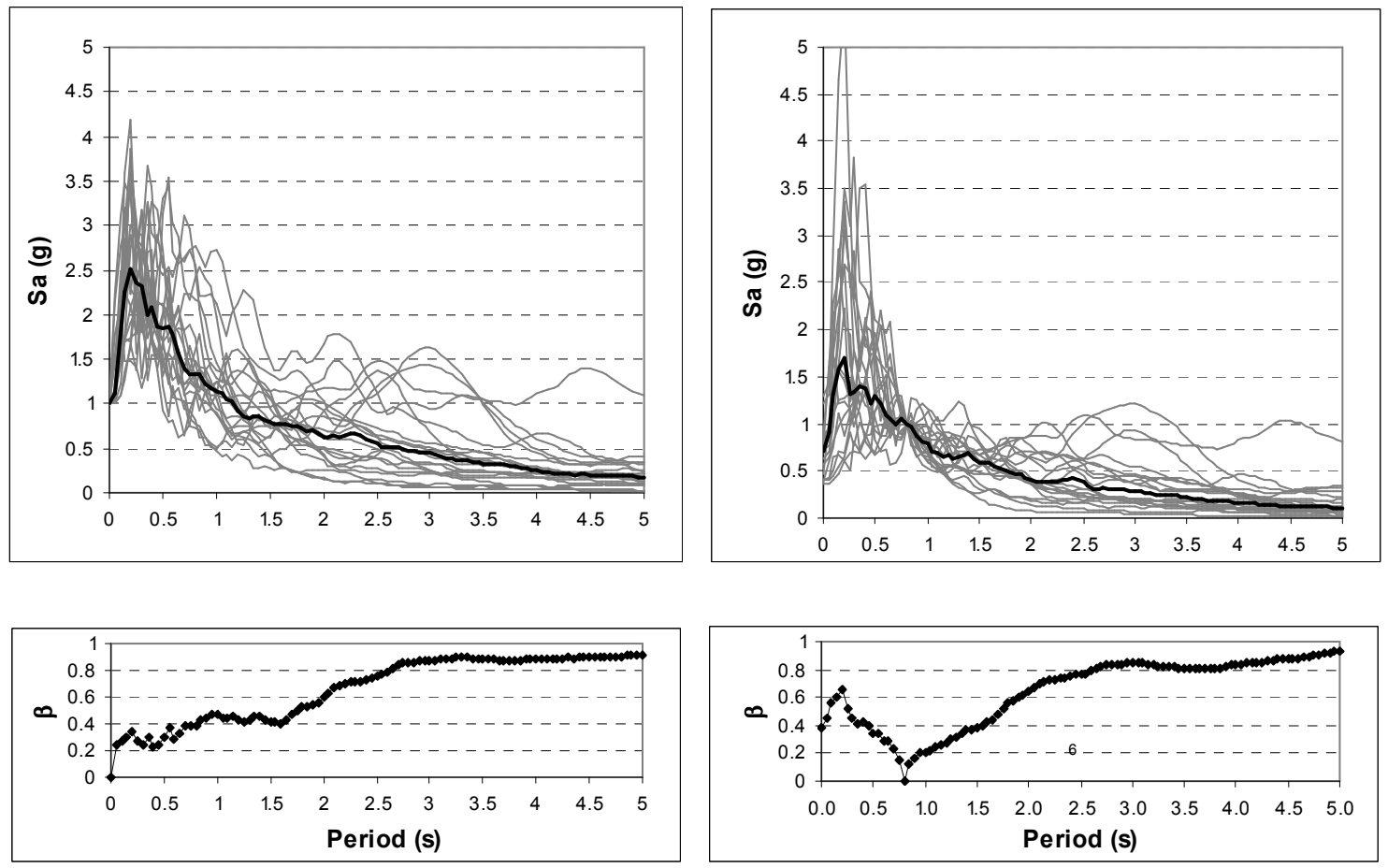

a. Scaled to $1.0 \mathrm{~g}$ PGA

b. Scaled to $\mathrm{S}_{\mathrm{a}}(0.8 \mathrm{sec})=1.0 \mathrm{~g}$

Figure 7 Spectral acceleration and lognormal standard deviation of the 20 ground motions scaled to the same PGA and $\mathrm{S}_{\mathrm{a}}$ 

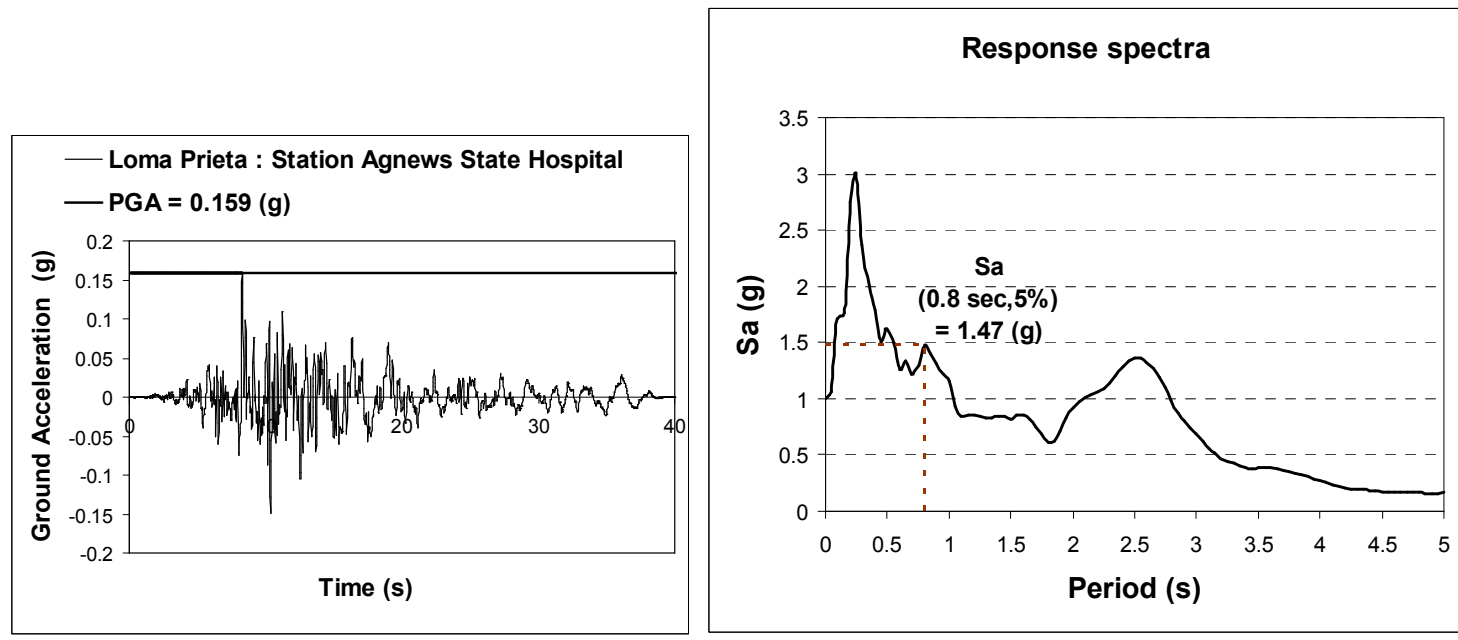

Figure 8 Accelerogram and Response spectra for the $1^{\text {st }}$ ground motion in Table 1
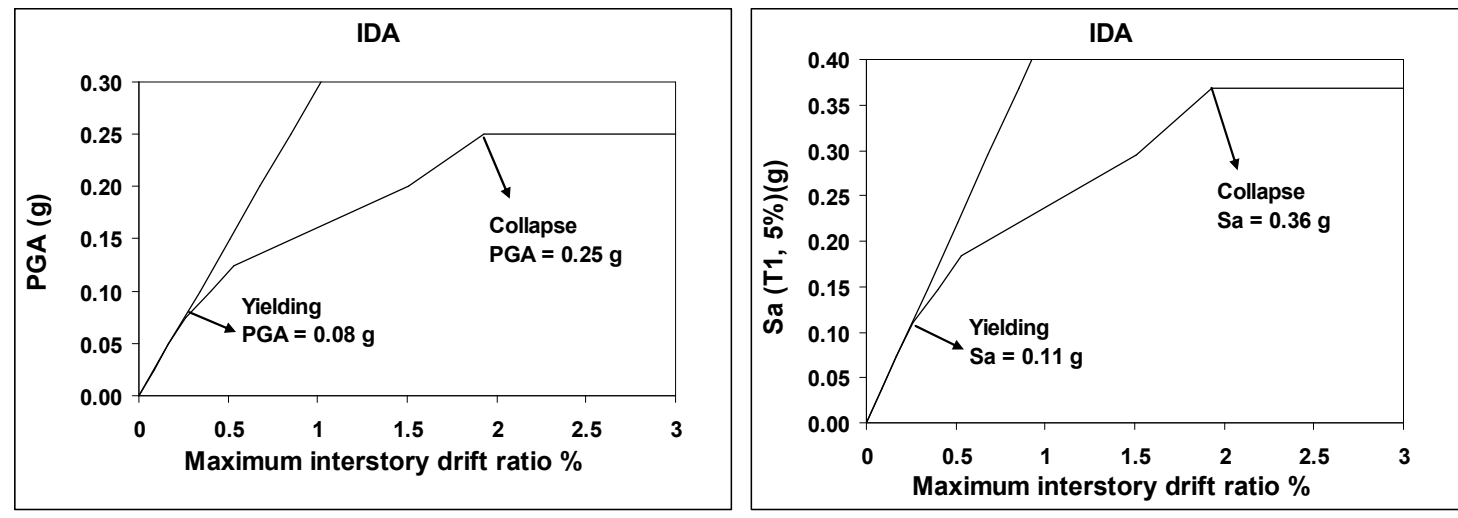

a. IDA with PGA as IM

b. IDA with $\mathrm{S}_{\mathrm{a}}$ as IM

Figure 9 IDA curve generated for the first ground motion record 

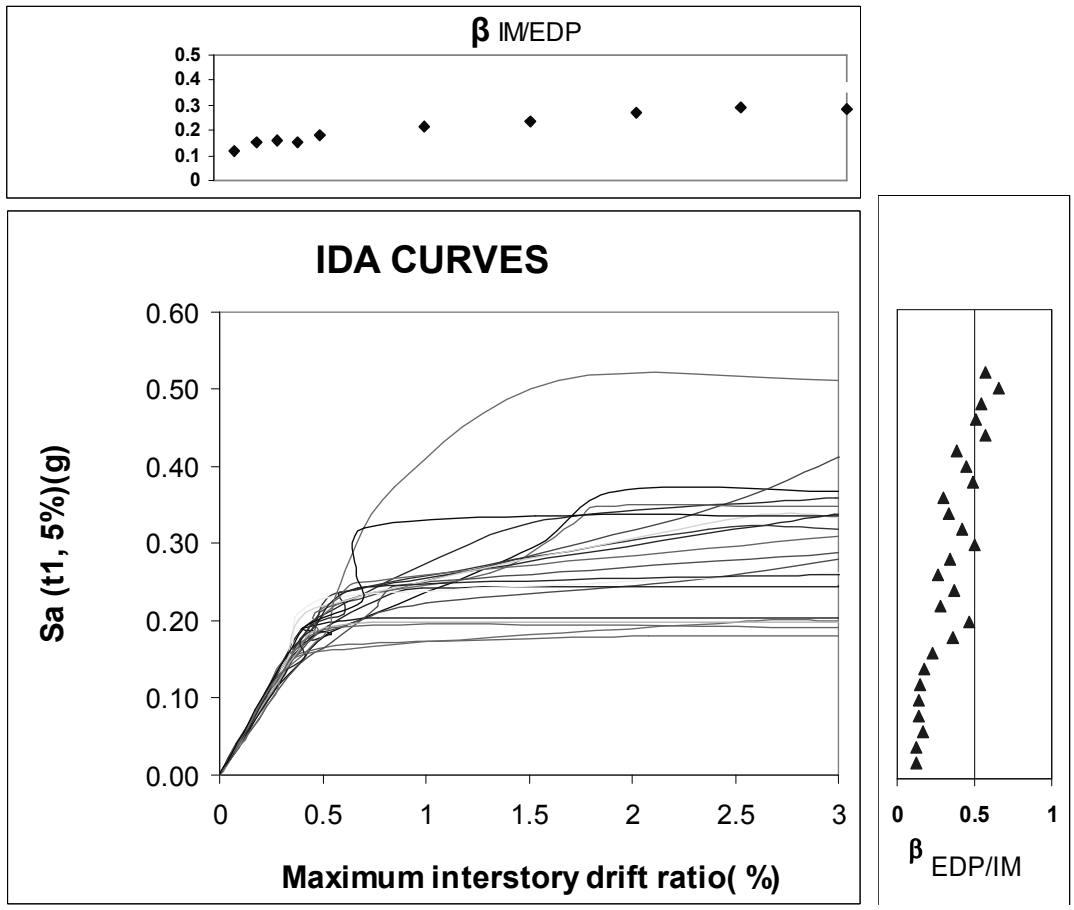

a. IDA curves for $I M=S_{a}\left(T_{1}, 5 \%\right)$
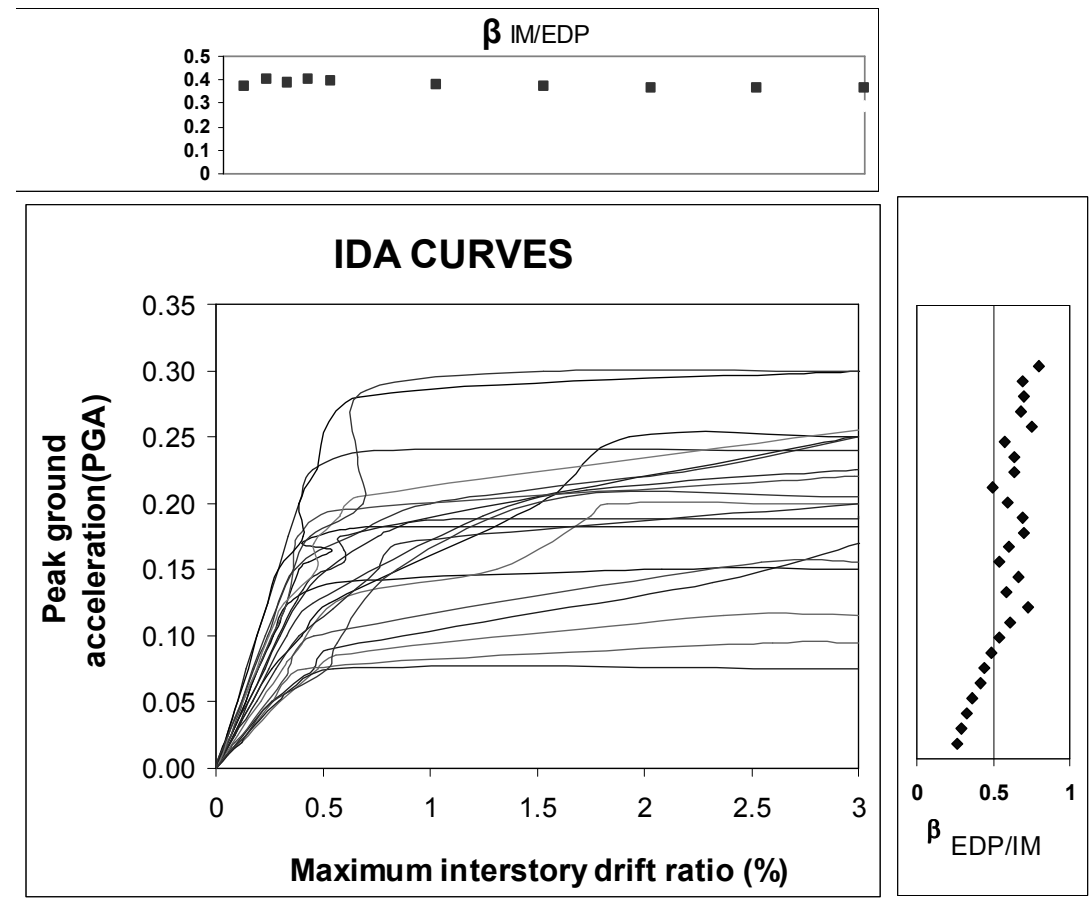

b. $I D A$ curves for $I M=P G A$

Figure 10 IDA curves for the sample building generated with the 20 ground motions 


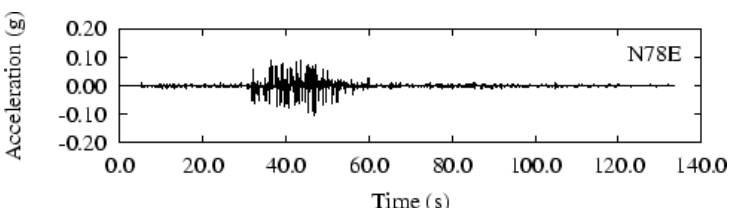

a. Accellerogram of N78E component

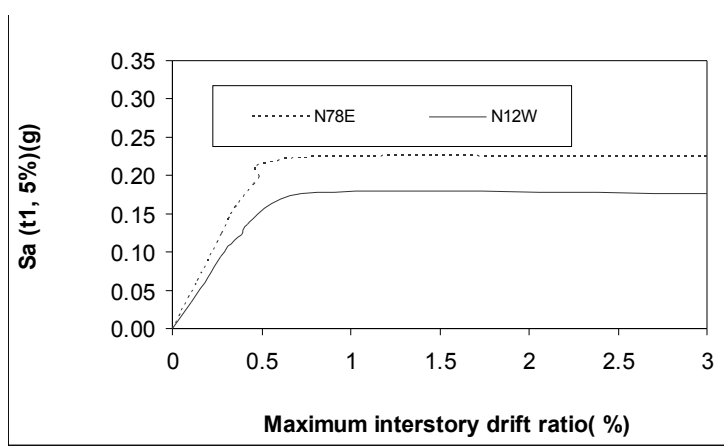

c. $I M=S_{a}\left(T_{1}, 5 \%\right)$

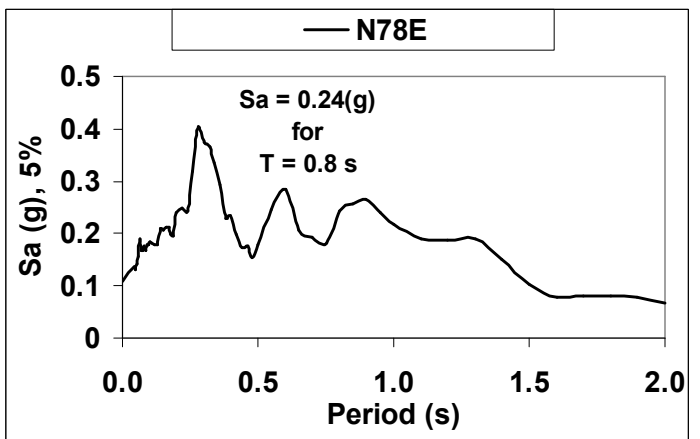

e. Response spectra of N78E component

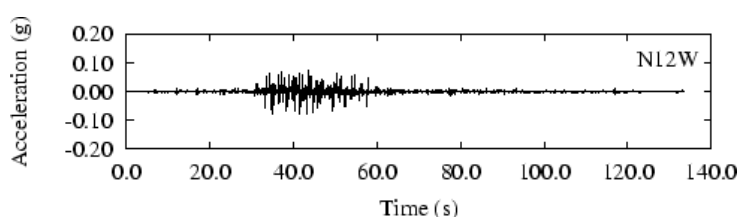

b. Accellerogram of N12W component

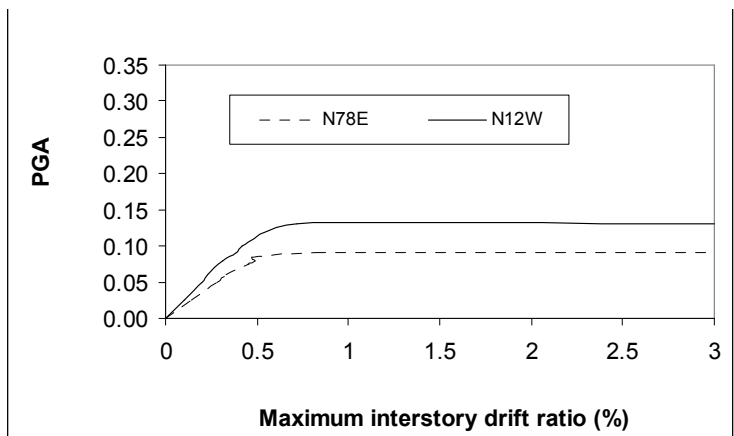

d. $\mathrm{IM}=\mathrm{PGA}$

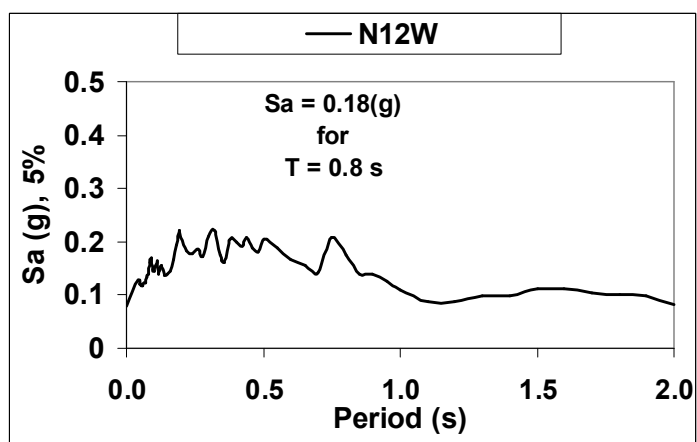

f. Response spectra of N12W component

Figure 11 IDA curves for the ground motions recorded at Ahmadabad during the Bhuj earthquake. 


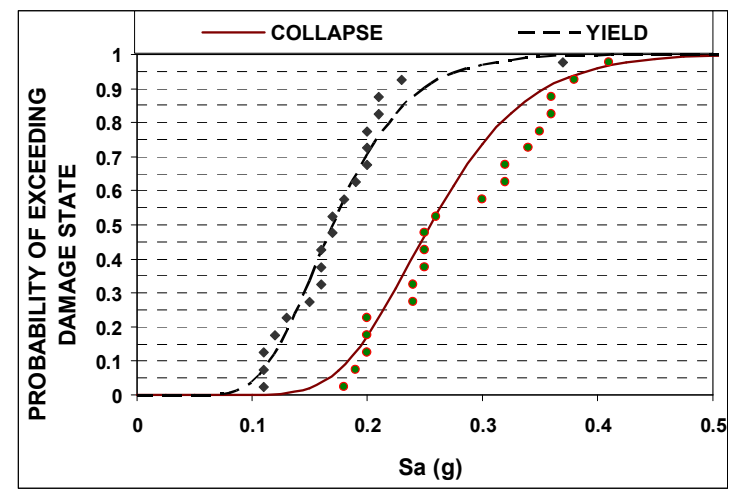

a. $I M=S_{a}\left(T_{1}, 5 \%\right)$

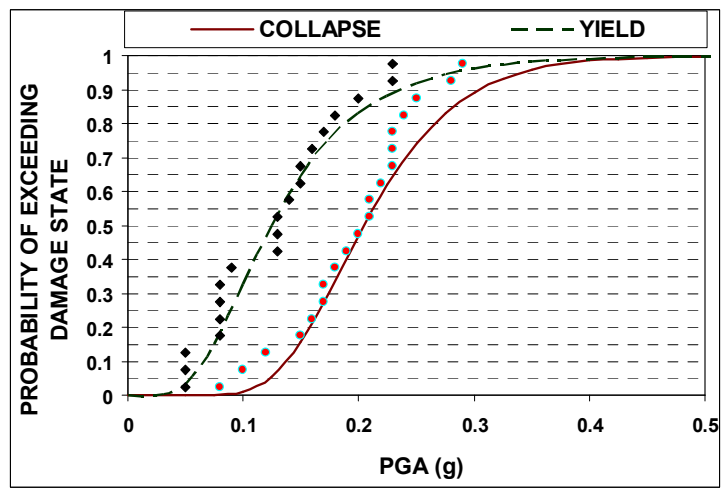

b. $\mathrm{IM}=\mathrm{PGA}$

Figure 12 Fragility curves for yielding and collapse damage states

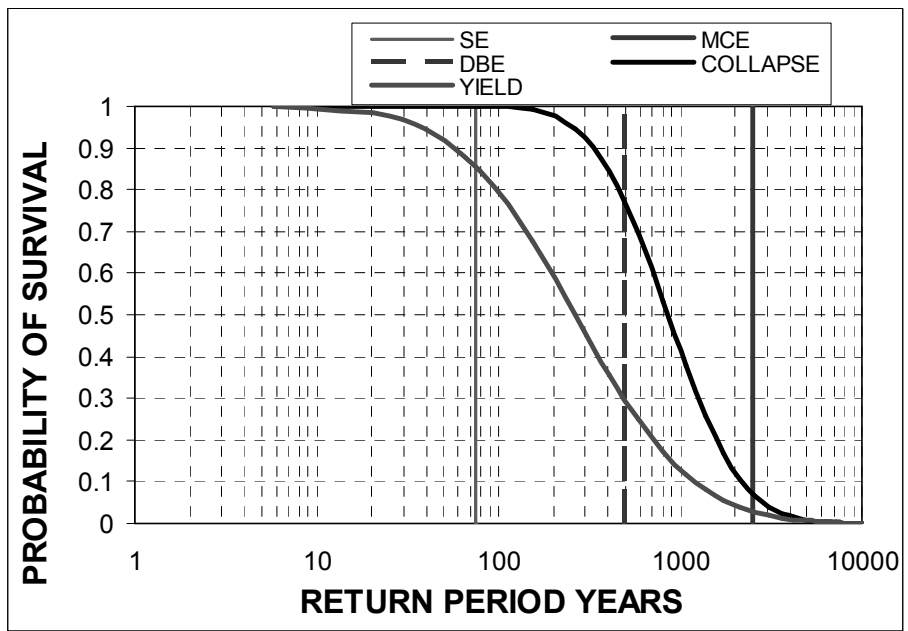

Figure 13 Hazard survival curves for the sample building 